\title{
THE STUDENT-CURATED EXHIBITION - A NEW APPROACH TO GETTING IN TOUCH WITH SCIENCE
}

\author{
Lorenz Kampschulte, Ilka Parchmann
}

IPN - Leibniz Institute for Science and Mathematics Education, Department of Chemistry

Education, Olshausenstr. 62, 24118 Kiel, Germany, kampschulte@ipn.uni-kiel.de

\begin{abstract}
Exhibitions provide a great variety of opportunities for shedding light on a scientific topic. By visiting an exhibition, and even more so by curating an exhibition, students gain great insights into scientific topics. Developing an exhibition offers students multiple ways of engaging with a topic, and presents a multifaceted learning environment, in which skills believed to be highly relevant for individuals' development into active, well-educated citizens can be developed. These skills support individuals in their private and working life, as well as enabling them to participate in a global society - with some of them (such as project management) being rarely addressed at school at all. To empower teachers to unfold this potential and create professional-like exhibitions within the tight time and budget frame of today's school life, a simple exhibition framework (EXPOneer) is presented in this article. Its design will be used in the EU-funded project IRRESISTIBLE. Using IKEA shelves, the system allows students to build their own professional-like exhibitions at school based on available knowledge and everyday resources, without distinctive craftsmanship or special tools. The incorporation of student-curated exhibitions (SCEs) into school practice will also be discussed, based on examples of current exhibition projects. After briefly sketching the theoretical background in the first part of this article, the second part aims to enable teachers, as well as other people working with students, to start their own professional-like exhibition project.
\end{abstract}

\section{Introduction}

Our society is subject to constant changes. One of the trends that can be observed over the last two decades is the continuing shift in the boundaries between professionals and laypeople; for example, jobs that were carried out only by professionals twenty years ago are nowadays carried out more and more by laypeople1. Theincredibly fast spread of the Internet has fueled this shift. This trend takes place on different levels, from a rapidly expanding group of 'expert amateurs' or 'makers', 'producing' all kinds of products with tangible (e.g., 3D printed objects) as well as intangible value (e.g., design templates for websites) in their living room, to large projects engaging the public in science and influencing political decisions at a nationwide level. To make it possible for people to actively participate in society, a growing number of well-educated citizens is needed. In 2002, the Partnership for 21st Century Learning (http:/ / www.p21.org/ ), a coalition of business community members, education leaders, and policy-makers, developed the 'Framework for 21st Century Learning' (Partnership for 21st Century Learning, 2011) to bring 21st century skills into the focus of US K-12 education. The framework highlights different skills that should be trained at school to

\footnotetext{
${ }^{1}$ What is meant by the term 'laypeople' in this article is people who are self-taught in a field (that is not their profession) and can thereby do things that would have required professional training in this field years ago (autodidacts).
} 
adequately prepare students for their future life, against the background of rapid societal changes. Where can students apply skills such as the 25 specified in the framework definition (Partnership for 21st Century Learning, 2009), including such diverse skills as:

- Work Creatively with Others

- Use System Thinking

- Communicate Clearly

- Be a Self-directed Learner

- Create Media Products

- Manage Projects

- Guide and lead others

And ideally using a combination of several of these skills in one single, authentic project? In the process of creating an exhibition, all 25 skills are routinely addressed. The four skills believed to be most important (so called 'super skills', http://www.p21.org/4Cs) - critical thinking, communication, collaboration, and creativity - are used in each exhibition project. Hence, exhibition projects offer promising learning opportunities for school students and enable them to become members of a scientifically literate society. By examining SCEs, the subsequent sections of this article will discuss the demands placed on individuals by a changing society and the skills with which students should be equipped in order to become active members of such a society. The second part of this article focuses on the implementation of SCEs in schools, using a recent example with the scientific topic of fats.

\section{Background: The 'expert amateur', public engagement and demands for multiliteracy}

The main characteristic of the rapidly growing group of 'expert amateurs' is that they do various things on an (almost) professional level, but for pleasure rather than as part of their profession. Although 'expert amateurs' are not new to our society, the rapid development of the Internet has given them a tremendous boost and expanded this group to a much broader community. Today, in its various expressions, the Internet affects many different parts of our life: from creating private things (e.g., designing photo books with publisher quality, or printing 3D objects at home) to the joint development of knowledge (e.g., online encyclopedias like Wikipedia or open-source software) to raising funds for (or funding) individual projects via crowdfunding. Searching for the reasons for this trend, Kuznetsov and Paulos indicate two crucial factors: "(1) easy access to and affordability of tools, and (2) the emergence of new sharing mechanisms" (Kuznetsov, \&Paulos, 2010). Shifting thelevel from the local activities (e.g., living room) of 'expert amateurs' to the public, the range and impact increases dramatically while still keeping the basic structure similar: laypeople working on professional tasks.

Although public engagement in science was a central part of scientists' work until the end of the $19^{\text {th }}$ century, it vanished almost completely in the $20^{\text {th }}$ century, when science communication was almost completely taken over by the emerging mass media (Könneker, 
\& Lugger, 2013). Today's demand for public engagement in science and technology started with the House of Lords' report in 2000 (House of Lords - Science and Technology Committee, 2000), with the aim of engaging non-professionals in the discussion of scientific research topics and allowing them to actually contribute towards the shaping of science policy. However, laypeople are not only involved in science policy; in some projects, they "participate in the scientific process itself as citizen scientists-for example, by counting stars or snails in projects such as Zooniverse or Evolution MegaLab" (Könneker, \& Lugger, 2013, p. 50). In a similar way, museums - in former times, places of secured knowledge presented by professionals - are increasingly confronted with the trend of 'expert amateurs' and public engagement. More and more institutions experiment with visitor-generated content - be it artworks created by visitors, or even the curation of exhibitions by the visitors (Gamerman, 2014). In the field of science centers and museums, this trend induces "a certain ambiguity, or tension [...]: on the one hand, a strong willingness to be "agents of change"; on the other hand, the fear of losing neutrality and of compromising their impartiality." (Bandelli, 2010)

The trend towards expert amateurs and public engagement, and the increasing foundation of society on these values, requires and, at the same time, promotes multiliteracy. This trend is specified in a model, originating from literacy pedagogy and introduced by the New London Group in 1996 (Cazden et al., 1996), which describes the necessity to react to two changes in communication needs when training students: "the increasing significance of cultural and linguistic diversity in a global economy, and the complexity of texts with respect to nonlinguistic, multimodal forms of representation and communication" (J ewitt, 2008, p.245). From the viewpoint of exhibitions, these nonlinguistic multimodal representations such as images, music, sounds, colors, writings, and so on, are of special interest. In the process of 'meaning making' (i.e., the construction of a message when developing the exhibition, as well as reading the message when visiting), several of these representations are used, each in a different way and to a different extent, but they all contribute to a larger picture. The advantage for students training in this area is that "the more a set of resources has been used in the social life of a particular community, the more fully and finely articulated its regularities and patterns become" (J ewitt, 2008, p.246).

Hence, the process of developing an exhibition with students includes a lot of tasks which require the active use and application of several of these multimodal representations, while also reflecting on the communicative role of the exhibition. In their paper on a studentgenerated virtual museum project (MUSE), Caroline Ho and colleagues point out the various tasks that offer multimodal learning opportunities:

Multimodal literacy [...] encourages a range of language-based skills including interpretative skills of content mediated through multimodal forms \& representations; evaluative skills in critically assessing the nature, representational techniques, explicit \& subtle effects of exhibits; oral and presentation skills in communicating proposed plans and perspectives clearly and effectively; and independent research skills in sourcing and adapting content from multiple sources for specific purposes. (Ho, Nelson, \& Müeller-Wittig, 2011) 
So, for students to become active members of society on both a local (i.e., expert amateur) and a global level (i.e., public engagement), multiliteracy is a prerequisite; it is essential if students are to be able to connect with and engage in this multicultural environment. Students' ability to flexibly use multimodal representations enables them to integrate content from multiple sources to form an individual opinion. The next section of this article discusses how these higher aims can be promoted by defining the learning goals and the skills that should be addressed in SCEs.

\section{Learning goals and skills in SCEs}

The EU-funded project IRRESISTIBLE (http:/ / www.irresistible-project.eu/ ) aims to engage students and teachers in debates about responsible research and innovation (RRI) in the area of modern science with relevance for societies, e.g., nanoscience and technology. The learning paradigm, as in most EU education projects, is inquiry-based learning (IBL). One of the objectives pursued by the European Commission by promoting IBL in various projects is to educate students to become scientifically literate citizens, by recognizing that students need personal experience with scientific inquiry in order to understand fundamental aspects of science. The approach of inquiry-based learning is based on students "find[ing] solutions to real problems by asking and refining questions, designing and conducting investigations, gathering and analyzing information and data, making interpretations, drawing conclusions, and reporting findings" (Krajcik et al., 1998, p.314). This process supports the development of important skills such as active critical thinking, research skills, and self-authorship (Hodge, Haynes, LePore, Pasquesi, \& Hirsh, 2008). Since most inquiry-based learning projects focus on scientific inquiry, many other abilities that could be equally developed in an IBL project, such as "knowledge-creation; teamworking; presentation; information literacy; ICT; problem-solving; creativity; project management." (Kahn \& O’Rourke, 2004, p.2), often take a back seat.

Developing an SCE on a scientific topic provides a lot of opportunities for training various skills, from initially exploring the topic to tightening the final screw. The skills that inquirybased learning focuses on are the core skills required when designing an exhibition. Students have to manage their own research, "formulate questions, plan their activity, and draw and justify conclusions about what they have learned" (Kuhn, Black, Keselman, \& Kaplan, 2000, p.497).

Starting in 2002, the Framework for $21^{\text {st }}$ Century Learning was developed by the Partnership for 21st Century Learning (2009), a US-based consortium of education leaders, business community members, and policy-makers. In comparison to the IBL approach, the industry- and output-related framework offers a more holistic view of $21^{\text {st }}$ century teaching and learning, including skills such as management, leadership and the production of results. Nevertheless, typical inquiry-based learning skills are still present in the framework. 
Besides the typical, more research-oriented inquiry-based learning skills that can be learnt/ are required, the construction of SCEs offers opportunities to advance many other ' $21^{\text {st }}$ Century Skills', for example, compiling the content for the exhibition questions the research capabilities of each individual. These skills are further trained by such tasks as: finding reliable sources, screening for different opinions on the topic, reflecting on the findings with respect to the possibleinterests of the author, the interests of society, and the overall message of the exhibition. In this phase, skills such as 'critical thinking and problem solving', 'information literacy' and 'media literacy' (Partnership for 21st Century Learning, 2009) are needed. Exhibition space is often very limited and, therefore, only the core messages of a topic can be focused on; this, together with the small size of text elements in exhibitions, limits the amount of possible ideas that can be presented to the visitor. This ability to focus on the very basic messages, along with the ability to maintain a clear focus on the potential target group of the exhibition, are well-known skills needed in the field of (science) communication.

Since creating an exhibition at school is by no means a task to be tackled single-handedly, successfully employing 'communication' and 'collaboration' skills is important for the project outcome. The power of collaboration - especially in the phase in which collective investigations lead to comprehensive content - is based on the fact that many different individuals researching and discussing their findings ultimately form a multidimensional picture of the topic being presented in the exhibition. Hodson (1998) describes this process of collaborative inquiry in the context of group experiments. In several case studies, Roth and Lee were even able to show that collective approaches could produce "much more advanced forms of scientific literacy [...] than any individual (including scientists) could produce" (Roth \& Lee, 2002, p.33).

To reach the goal of the EU project IRRESISTIBLE, which is to engage students and teachers in debates about responsible research and innovation (RRI), learning modules on different scientific topics have been developed. Each module is based on inquiry-based learning, and is implemented in a "6E model" (Kampschulte, 2014, August 29), a version of Bybee's 5E model (Bybee, 2002) extended with an exchange phase between the elaborateand the evaluate phase. Seeing the exhibition project as an IBL task in itself, the modules combine two stages of inquiry-based learning: in the first part of each thematic module, a scientific inquiry project is initiated. Here, students should experience authentic scientific work, including planning experiments, conducting measurements, and interpreting the subsequent data. In the second stage, the content for the exhibition is researched by taking a broader perspective on the topic, based on the authentic experimental experience from phase one. Using the knowledge gained in the two different IBL phases facilitates the construction of a multidimensional, authentic picture of the topic in the final exhibition. In the past, Sleeper and Sterling (2004) effectively combined these two inquiry-based approaches in a fifth-grade science project, with students first researching a scientific problem in the lab, which was subsequently presented in a small exhibition. Following a similar approach, a recent summer 
camp 'Science and Science Communication' offered students the possibility to develop their own research project and to develop a multimedia presentation at the end (Tirre, Kampschulte, \& Parchmann, accepted). These projects indicate that the combination of two inquiry-based learning stages can be successful. The EU project IRRESISTIBLE builds upon this approach.

An exhibition requires not only a profound (scientific) content but also a thorough design. Creating an exhibition without a design is not possible - even if you think of just a few handwritten sheets of paper pinned to the wall', there is a message behind the pure content written on the paper (e.g., influenced by the type of handwriting, or the visitor asking himself/herself why it is handwritten and not printed, etc.: see discussion of multimodal representations above). In terms of exhibitions, the most basic communication tools are objects, texts, and pictures. The next level of tools is those reaching out to additional senses: sound, haptic opportunities, or even sometimes smells. In addition to these, there are further manifold tools which can be used to enrich the message being sent to the visitor. Or as Hedley Swain describes it fittingly:

Added to this is something that is less easy to define. It is the way words, objects, and pictures are combined and grouped and added to by such elements as space, light, and colors - props that help create a context, atmosphere, and ambience for displays. (Swain, 2007, p.217)

These 'messages between the lines' are what makes the difference between a nice exhibition and a memorable exhibition. This is why museum professionals believe that the design of exhibitions is closely related to (the communication of) the content, or, as renowned museum consultant and researcher Beverly Serrell puts it: "design plays a crucial role not just in presenting content, but in actually creating it" (Serrell, 2006, p.33). Aligning the message with the design of SCEs is one of the most interesting but also challenging parts of the project for students (and teachers). Expression possibilities in SCEs are limited - but this can be beneficial, since a) the development of a coherent message using all the possible tools is very time-consuming, and b) in the daily routine of museums, similar restrictions apply in terms of space, time, and budget. The editing process required during the development of an SCE will increase students' evaluation competency regarding content and presentation quality, and will ultimately contribute to their multimodal agility and media literacy in many related fields.

In summary, theimmense diversity and quantity of the tasks involved in the development of an SCE renders it the perfect environment in which to train and reflect on students' skills. As SCE projects usually run for several weeks or even months, they engage students to work on the topic at deeper levels. This long-term commitment, especially in conjunction with generating and testing hypotheses, is known to promote students' (intrinsic) motivation (Marzano, Pickering, \& Pollock, 2001). The multitude of skills that students get to know, reflect on, and develop during an exhibition project - from actively using multimodal representations to increasing scientific literacy, through collective research, to internalizing teamwork and project management - will hopefully assist them in ultimately participating 
and engaging in modern society. Or, as Linda D'Acquisto puts it in a nutshell: "These qualities make school museums much more than interesting projects; they are catalysts for student learning" (D'Acquisto, 2006, p.4).

\section{A simple, modular exhibition system for schools: EXPOneer as part of the EU project IRRESISTIBLE}

Exhibitions focusing on art or history topics are typical examples of exhibitions created by students. In contrast, scientific matters are less frequently the topic of student exhibitions. If science is the main focus of an activity, it might show up as a kind of science fair, presenting the contributions of students (or groups of them) as part of a competition, thus being more a line-up of individual mini-shows than an exhibition on a common topic. For visitors, experiencing this kind of exhibition is highly ambivalent: thrilling due to passion and excitement of young scientists, and discouraging due to the overwhelming offer of information, presented in many different ways and often in a slightly disorganized design. On the other hand, in the art scene, there are high-end exhibitions developed by teenagers, with a comprehensive design-follows-content approach. The Teen Art Gallery (teenartgallery.org), established in NewYork in 2010, is probably one of the most well-known exhibition projects (Strausbaugh, 2011), although several projects with a similar focus also exist. However, it should be noted that these exhibitions are usually created by special interest groups, i.e., students who are devoted to the topic and do this in out-of-school activities, not as a class project. Nevertheless, the fact that these projects exist is encouraging, as it suggests that it is possible to create student-curated science exhibitions at school at a professional-like level.

By holding discussions with teachers and searching for reasons for why exhibitions are not that common at schools, we found out that a lot of teachers were interested in creating professional exhibitions with their students, but were worried about the immense amount of time involved and the lack of a structure to get such a project started and realized. So, when we started developing a framework for SCEs, we had five boundary conditions:

- Fast: the construction period of an exhibition has to be short (so students have time to focus on content and design)

- Easy: it must be easy to build (students do all the work, no special tools, materials, or craftsperson should be involved)

- Flexible: the exhibition must be flexible and re-usable (so a new group of students can build a different exhibition the following year)

- Accessible: the material should be easily accessible (construction manuals online (free), building material from local stores)

- Inexpensive: the exhibition must be low-cost (so it is affordable for schools)

With these ideas in mind, the EXPOneer exhibition system for SCEs was developed and embedded in the project IRRESISTIBLE. For the basic frame of the SCE, a shelving system was needed that was easy to build, flexible, inexpensive, and, ideally, available throughout 
Europe. In general, there are many options from different suppliers that could be used, but building on the IKEA Kallax-series brought the additional advantage of shelves with equallysized compartments that - when adding various content elements - remain highly flexible during the process. To equip the shelves with content and thus transform the frame into an exhibition, a variety of so-called elements were developed. These ranged from simple textand image-panels to showcases with LED lighting and frames housing tablet PCs for presenting digital content. The text- and image-panels were designed with standard presentation software (e.g., Microsoft PowerPoint). For the task of printing on the adhesive foil, an online printing provider was used. All other materials required can be bought at a local building center or at common online shops, and, although the skills for building the elements vary, all of the elements can be built by students.

The time frame for an exhibition project, including research, development, and construction, is usually around 8 - 10 weeks, with the average student workload comprising 2 - 3 hours per week (for details, see example below); the time needed for actually setting up a two-shelf exhibition with a class is only about one day ( 6 - 9 hours, assuming good project management and all required materials being present).

The Exhibition Guide, with an introduction to creating SCEs, ideas on how to combine the modules, all step-by-step manuals on how to build the content elements, material and tool lists, and so on, can be downloaded from the EXPOneer webpage (Kampschulte \& Schwarzer, 2014). The framework and one example of the pilot projects for the IRRESISTIBLE module are described in the following sections.

\subsection{Conceptual Framework}

In general, exhibition projects are highly flexible and adaptable to the school environment. The project can be widely adjusted, from a one-class-one-week project, to a joint production of a science and an art course running over several weeks, to using (free choice) afternoon classes to support an interdisciplinary science class. The general workflow is briefly depicted in Figure 1. The first stage is to define the general topic and the teams that will be part of the exhibition project. Usually, the science team is the executive team, thus responsible for the main project coordination. After developing the thematic core ideas, parts of the work are assigned to the other teams, while constantly discussing and re-aligning the flow of ideas and concepts to secure a coherent overall picture for the exhibition. 


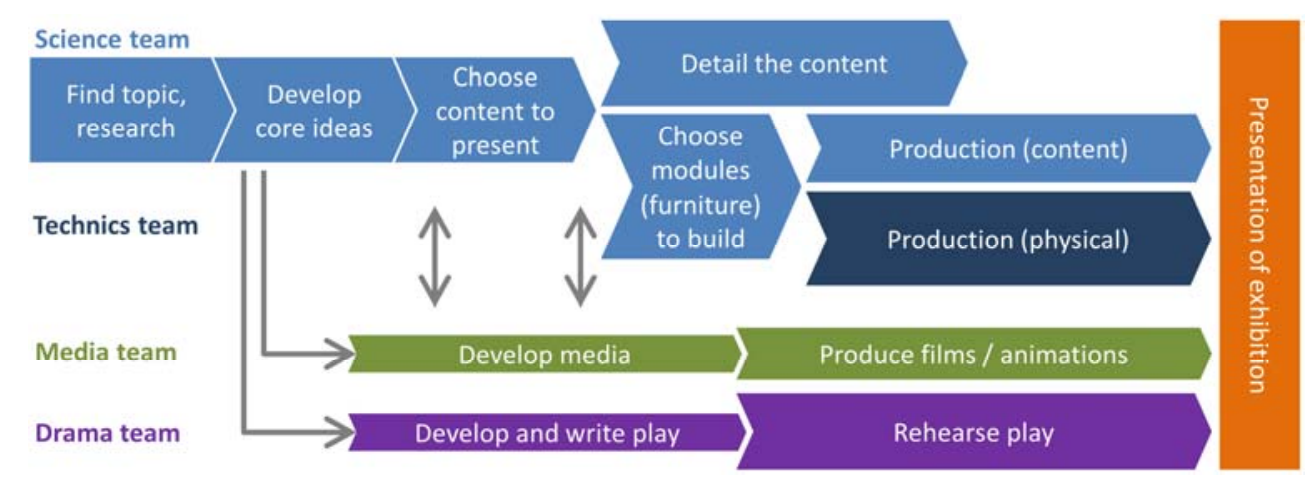

Figure 1: Project workflow in a student exhibition project.

These settings of collaborative work between students of different interest groups serve as incubators for mutual enrichment: Students of, for example, a drama group (that might never before have heard of topics such as nanoscience) are confronted with the task of writing a play about the risks and benefits of nanotechnology. On the other hand, students of the science class are confronted with the task of explaining topics such as nanotechnology in simple words to their peers from the drama group, and discussing whether the ideas presented in an artistic piece suit the exhibition topic.

In order to provide more information about the single steps involved and the work to be done within each step, Table 1 shows the detailed workflow of a typical project - an exhibition created by two stakeholder groups: a science team, and an art team. This workflow example is based on the project described in more detail in Section 3.2. In the generalized form presented here, it should work as a backbone for most SCE projects. Further ideas and options for some of the steps are discussed below. 
Table 1: Workflow of a typical exhibition project, created by a science and an art team; [M\#] indicates project milestones, [WP\#] indicates work packages.

\begin{tabular}{|c|c|c|c|}
\hline time & exhibition construction & content & design \\
\hline $\begin{array}{l}\text { weeks until } \\
\text { opening }\end{array}$ & entire team & science team & design team \\
\hline \multirow[t]{2}{*}{10} & \multicolumn{3}{|l|}{ [M1] project start, kick-off } \\
\hline & \multicolumn{3}{|c|}{ [WP1] introduction; choice of topic for the exhibition; appointment to the teams } \\
\hline \multirow[t]{6}{*}{9} & \multicolumn{3}{|l|}{ [M2] exhibition topic is fixed } \\
\hline & & $\begin{array}{l}\text { [WP2a] first research on the topic; showing the } \\
\text { whole width of the topic; localize interesting } \\
\text { topics; develop guiding ideas / topics }\end{array}$ & \multirow{3}{*}{$\begin{array}{l}\text { [WP2b] introduction to exhibition design; } \\
\text { develop an approach for realization integrating } \\
\text { the multitude of design options; reflect on } \\
\text { specific aspects and requirements of } \\
\text { presentations in exhibitions and of the } \\
\text { EXPOneer system in particular; write down } \\
\text { design framework; develop first design options } \\
\text { and sketch them }\end{array}$} \\
\hline & & [M3a] guiding topics fixed & \\
\hline & & \multirow{3}{*}{$\begin{array}{l}\text { [WP3a] detailed research on guiding topics; } \\
\text { developing first presentation ideas; create } \\
\text { thematic mood-boards with text, image, and } \\
\text { exhibit ideas; obtain exhibits; develop first } \\
\text { prototypes for hands-on exhibits; specify topics } \\
\text { and content }\end{array}$} & \\
\hline & & & [M3b] framework for design fixed \\
\hline & & & $\begin{array}{l}\text { [WP3b] detailing of the design concepts; } \\
\text { preparation of the challenge for exhibition } \\
\text { design; test of designs conforming to the } \\
\text { framework requirements }\end{array}$ \\
\hline \multirow[t]{8}{*}{6} & \multicolumn{3}{|c|}{ [M4] presentation and discussion of guiding topics (mood-boards) and design ideas (challenge) } \\
\hline & & $\begin{array}{l}\text { [WP4a] optimizing guiding topics after } \\
\text { discussion }\end{array}$ & $\begin{array}{l}\text { [WP4b] optimizing and finalizing the exhibition } \\
\text { design }\end{array}$ \\
\hline & & [M5a] topics and content fixed & [M5b] exhibition design fixed \\
\hline & & $\begin{array}{l}\text { [WP5a] work out the details of content: group } \\
\text { content fitting the text structure; write texts; } \\
\text { research images in print quality; prepare }\end{array}$ & $\begin{array}{l}\text { [WP5b1] design a poster for advertising the } \\
\text { exhibition (again with a challenge?) }\end{array}$ \\
\hline & & $\begin{array}{l}\text { exhibits (cleaning, fixing, mounting); refine } \\
\text { prototype for hands-on exhibits }\end{array}$ & $\begin{array}{l}\text { [WP5b2] public relations: define and start } \\
\text { activities, e.g., talking to local newspapers, } \\
\text { announcement on school webpage, and so on }\end{array}$ \\
\hline & & [M6a] texts/ images / exhibits fixed & [M6b] poster and PR activities fixed \\
\hline & $\begin{array}{l}\text { [WP6] define exhibition structure } \\
\text { content into the designed layout, }\end{array}$ & $\begin{array}{l}\text { umber and positioning of shelves, places for spec } \\
\text { necessary shorten texts and optimize layout }\end{array}$ & ial and hands-on exhibits, and so on); insert \\
\hline & & $\begin{array}{l}\text { [ WP7a] proofreading of transparencies with } \\
\text { reference to content }\end{array}$ & $\begin{array}{l}\text { [WP7b] scrupulous checking of transparencies } \\
\text { with reference to design }\end{array}$ \\
\hline \multirow[t]{2}{*}{2} & \multicolumn{3}{|c|}{ [M7] exhibition structure und transparency layout fixed } \\
\hline & \multicolumn{3}{|c|}{$\begin{array}{l}\text { [WP8] commission the printing of adhesive foils; buy shelves and building material; finalize hands-on exhibits; check transparencies } \\
\text { when printed; obtain tools for building day; intensify PR/advertisement }\end{array}$} \\
\hline \multirow[t]{2}{*}{0} & \multicolumn{3}{|c|}{ [M8] exhibition 'ready for building' } \\
\hline & \multicolumn{3}{|c|}{ [WP9] building day: briefing of students; appointment to the teams; building the exhibition } \\
\hline \multirow[t]{2}{*}{0} & \multicolumn{3}{|l|}{ [M9] exhibition completed } \\
\hline & \multicolumn{3}{|l|}{ [WP10] preparation of opening } \\
\hline 0 & \multicolumn{3}{|c|}{ [M10] opening of the exhibition } \\
\hline-1 & \multicolumn{3}{|c|}{ [M11] wrap-up: reflection on the project; party for exhibition development team } \\
\hline
\end{tabular}

The first task in an exhibition project is to hold a kick-off meeting [M1]: When introducing students to the idea of developing exhibitions, they should get a first understanding of what an exhibition is, and they should learn what the specific characteristics and challenges of 
presenting a topic in a museum setting are. This is probably done best by visiting a museum and discussing on-site the question of how content is provided (it might be interesting to ask a curator what his/her thoughts were when creating the exhibition). If a real visit is not possible, showing examples of various exhibitions on slides can also focus attention on the relation of objects, images and text. Special attention should be paid to the hierarchical text structure of exhibitions, which greatly helps to make the content perceptible to the visitor (overview: http://www.exponeer.de/index.php/en/bauanleitungen-en, deeper insight: Serrell, 1996). Further on in the kick-off meeting, the overall topic of the exhibition should be defined. The topic should be discussed with the help of guiding questions such as

- What does a visitor expect from an exhibition on that topic?

- What might be of special interest? (e.g., local connection)

- What will make the visitor curious about the topic?

- What prejudices might a visitor have? but also

- Who is the visitor of our exhibition?

- What is the target group?'

Last but not least, in the kick-off meeting, the students have to be assigned to their team. An optimum team size is about 3 - 4 students, with teams in some project phases working closely together. The proportion of science to design teams should be more or less equal.

Another aspect that enriches the project outcome and offers further opportunities to learn ' $21^{\text {st }}$ Century Skills' is a teaching unit How to do Research Carefully'. This could either be part of the kick-off phase or could be included in the first research phases up to milestones [M3a]/[M3b]. The unit should focus on two aspects: For the science teams, the importance of searching for different opinions on a given topic should be highlighted, and the credibility and reliability of sources should be examined. For the design teams, copyright issues should be questioned and reflected upon and the value of the design should be discussed. Nevertheless, both foci are relevant for both groups.

Besides writing short, meaningful texts, one of the biggest challenges in developing an impressive exhibition is the arrangement and interplay of objects, texts, and images. Avoiding a plain line-up of content building blocks, and instead grouping them into meaningful arrangements that form a much stronger (or even new) message is a task with which professional curators also struggle. A unit 'Organize your Showcase' could help to emphasize the impact which the arrangement of materials can have, as well as training students in how to use the technique to develop a better exhibition. In this unit, a set of cards containing photos of different exhibition elements (objects, images, paintings, places, people, etc.) is spread out on the table. Taking a topic that is not related in any way to the planned exhibition topic may highlight this as a 'training unit', and not as part of the project development. Each student team chooses 3 - 5 cards that they believe tell a story when connected in the right way. Assigning random cards to the groups is possible as well, but makes the exercise more challenging. Then, students' task is to write a short text (600 
characters) connecting the elements. The complexity of this unit can be easily adapted to the grade level (and time available).

Milestone 4 [M4] 'presentation and discussion of guiding topics' is important for the exchange of ideas and progress between the science and the design teams and enough time should be allocated to it. Learning what the other teams have developed so far, and seeing how these ideas align with the concepts of the own team is a fundamental step in forming a coherent presentation of the exhibition. From there onwards, the work is again split up into a science and a design strand, finalizing the content, presentation, and layout, as well as working on the public relations activities.

Work package 9 [WP9] is probably the most complex task in the creation of an SCE: the day (or period) of actually building it. Thorough preparation is essential for survival, as is a distinct project and time management for the crafting activities. For building an exhibition based on the EXPOneer system, a planning sheet indicating tasks, times, and team sizes is available for download on the EXPOneer homepage (http:/ / www.exponeer.de/ index.php/ en/bauanleitungen-en).

For the exhibition opening, again, various options are conceivable: From inviting other classes to join an opening ceremony with an introductory talk during school hours, to organizing a science day for the whole school with further science-related activities surrounding the exhibition, to inviting family and friends to a festive evening celebration. Whatever kind of event is chosen, this final focal point is very important for the project progress. The entire schedule must be aligned with this final focus in order to ultimately get the exhibition finished.

\subsection{Exemplary project: The exhibition 'Fat!'}

One project using the EXPOneer system was an SCE on the scientific topic of fats and their influence on our society. It was a co-production of a chemistry and an art course, both mixed courses of $10^{\text {th }}$ and $11^{\text {th }}$ grade students, at an upper-level secondary school in Germany. The duration of the whole project was eight weeks, taking place in spring and early summer. In week two, the students got an introduction to 'How to Build an Exhibition' from a science museum curator, in which various examples of exhibition concepts were demonstrated, and students were familiarized with the basics of exhibition planning and text writing. In the following weeks, the content was subsequently refined, and a design and layout concept was developed. After the students had reduced the text lengths several times, the final layout was prepared and sent to the online printing provider. The building day was very well organized; 45 students worked in three shifts of 15 individuals, finalizing the exhibition in a little less than seven hours.

The exhibition was made up of two large shelves, supplemented by two hands-on demonstrations (see Figure 2). The shelves were equipped with text-, chart-, and imagepanels, showcases, and three tablet PCs displaying different videos created by the students. 
As hands-on activities, the students developed a body mass index (BMI) calculation station, and sewed a 'fat suit', a pajama-like suit that adds $5 \mathrm{~kg}$ to the person wearing it.
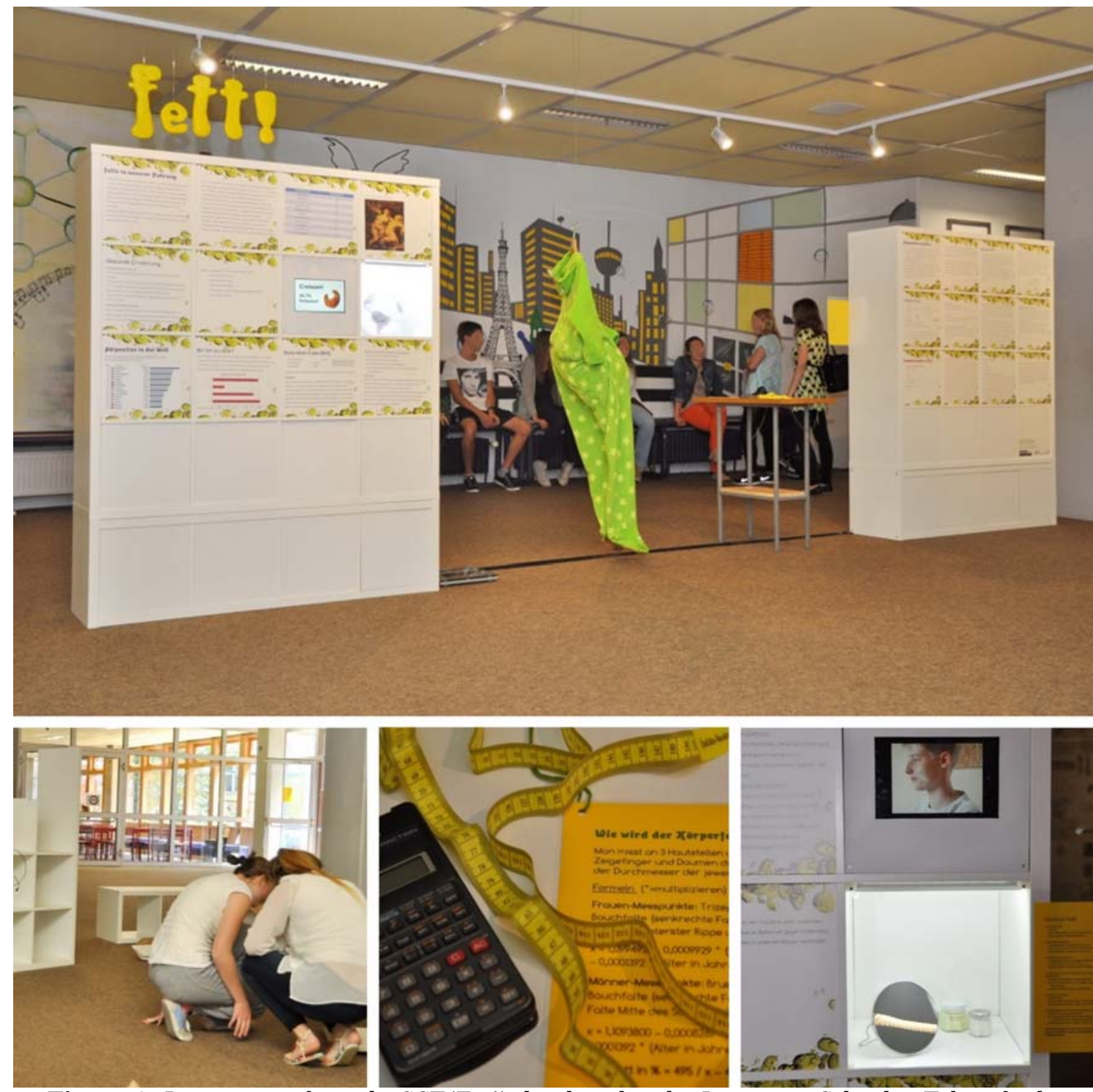

Figure 2: Impressions from the SCE 'Fat!', developed at the J ungmann School in Eckernförde, Schleswig-Holstein, Northern Germany.

A paper-pencil questionnaire was administered before and after the intervention (pre-post) for the purpose of evaluating the exhibition process. The questionnaire was created from existing evaluation tools for a student lab (Boll, 2013; Schwarzer \& Parchmann, 2015), but adapted to the situation of developing an exhibition. With $\mathrm{N}=44$ students, the exemplary results presented in the following section have a piloting character for the project IRRESISTIBLE. The art course consisted of 20 students, with girls and boys equally distributed; the chemistry course included 19 female and 5 male students.

After the project was completed, students were asked how much time and where they spent developing the exhibition (see Figure 3): the graph clearly shows that most of the time was spent at school: an average of $8 \mathrm{~h}$ per student for the whole project. In addition, they 
spent about $3 \mathrm{~h}$ at home working on the project, plus an additional $3 \mathrm{~h}$ at school on the building day. In total, each student spent an average of $13.5 \mathrm{~h}$ on the project. Additionally, students were asked how they perceived the time they had to invest in the project (scale: 'could have been more', 'ok', 'too high', 'far too high'). 70\% of students believed the time they invested was reasonable.

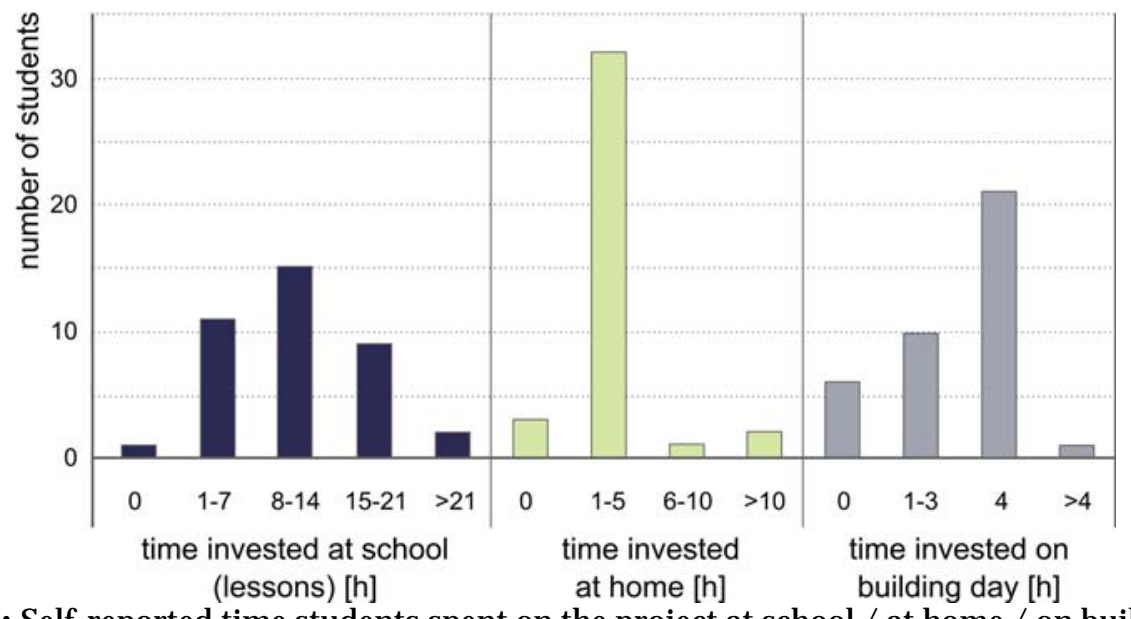

Figure 3: Self-reported time students spent on the project at school / at home / on building day. $\mathrm{N}=38$.

In the post-questionnaire, the students were also asked to rate their motivation in the different project phases on a four-point Likert scale $(1$ =high, 2 =rather high, 3 =rather low, 4 =low). Looking at students' average motivation over the whole project, the art course $(\mathrm{N}=$ 19) scores were at a medium level $(\mathrm{M}=2.47, \mathrm{SD}=1.01)$. The chemistry course students $(\mathrm{N}=20)$ indicated a slightly lower motivation level with a mean score of $\mathrm{M}=2.72$ ( $\mathrm{SD}=$ 0.92). The difference is not statistically significant. However, looking at the different phases, some interesting variations can be observed (Figure 4): For the chemistry course, the motivation in the earlier stages was higher and decreased towards the end of the project. The motivational pattern of the art course was the opposite, with a lower level at the beginning and an increase towards the end. This result is in line with the assumption that students have a higher motivation to do those things they like best, i.e., the chemistry course liked researching and developing the scientific content, the art course liked creating the real exhibition. Another factor that probably influences this behavior is an incident that occurred in the middle of the project: A heated discussion between the groups about the exhibition texts. The chemistry team delivered texts containing lots of information, but not suitable at all for presentation in an exhibition. The layout team handed the texts back with the request to shorten them to a length fitting the layout. However, most of the chemistry team refused to do so, claiming that the reduction would cause the text to lose important content. So, the layout team started to shorten the texts, demotivating the chemistry group. This incident is prototypical, since it will happen at some point in almost every exhibition project. It can be seen as an important point in the learning process during which skills such as goal orientation and communicative skills can be trained. However, such incidents should also be prevented 
or at least mitigated for the sake of keeping adequate motivational levels, e.g., by defining text lengths early on.

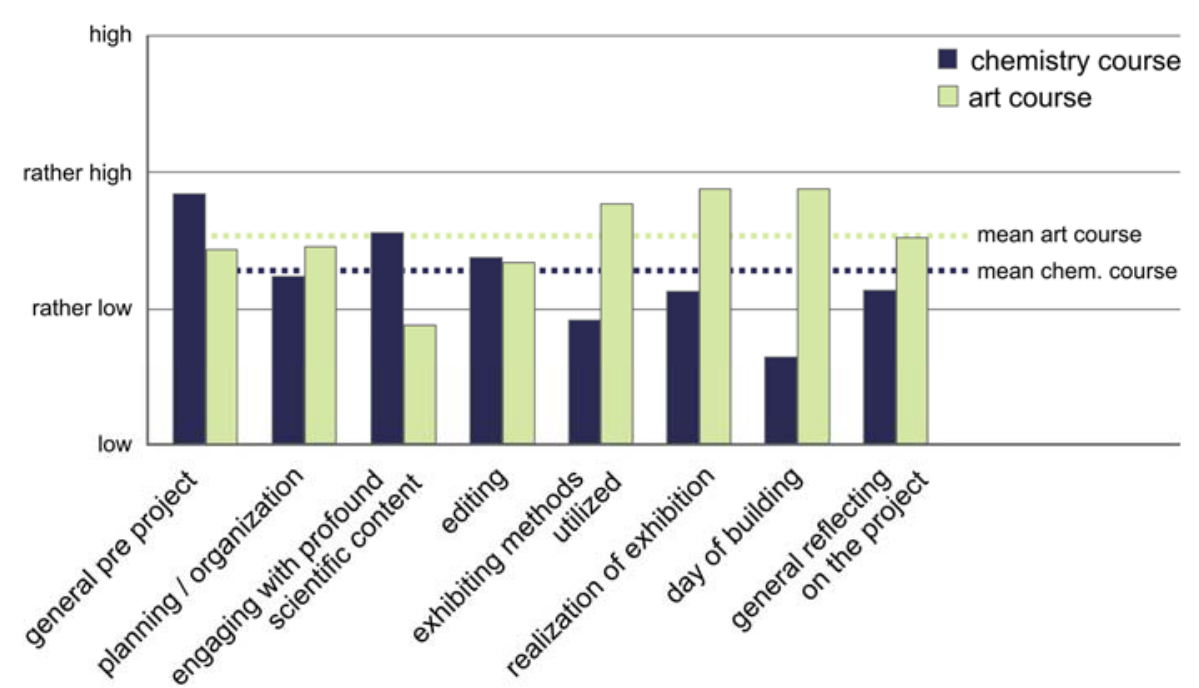

Figure 4: Trend in student motivation as the development of the SCE progressed. $N_{\text {art }}=19, N_{\text {chem }}=20$.

In the questionnaire, two items were included which asked students what they liked, and what they did not like. The questions were open-format items asking for three answers to each question. The authors read the answers, analyzed the content and inductively formed nine categories. Criteria describing these categories were developed and applied to code the answers. The results for the nine categories can be found in Figure 5. Again, the conflict on the texts is very present and clearly shows up on the 'did not like' side ('collaboration between courses', 'communication', to some extent 'project management'). As well, the time invested and time pressure was stated several times. The great advantages of an exhibition project can be seen in the research (science for one group, design options for the other group) and the development activities, in the team work and cooperation, as well as in the extended amount of autonomous work. 
What did you not like?

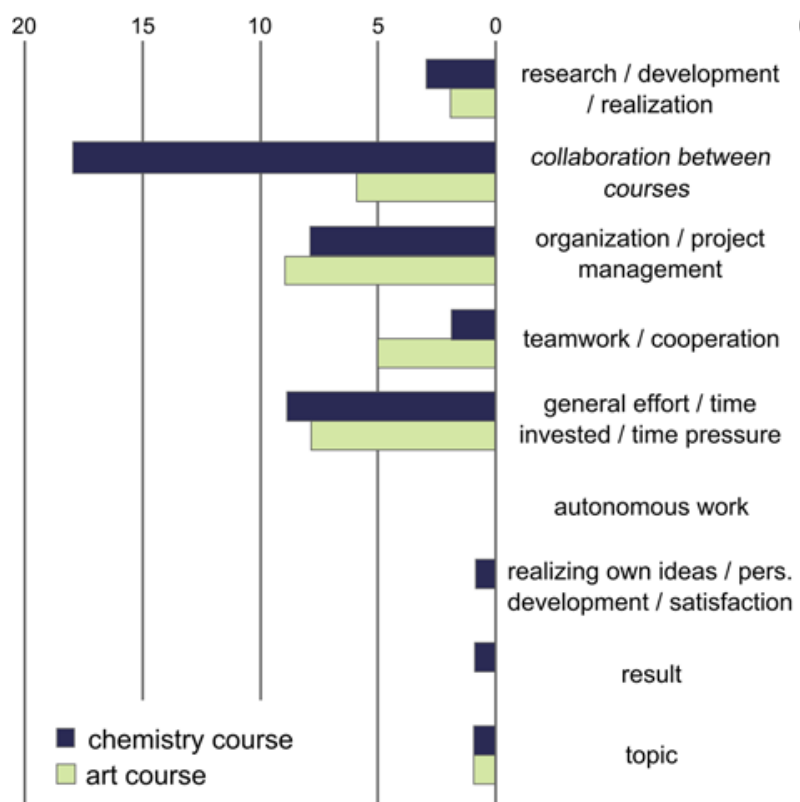

What did you like?

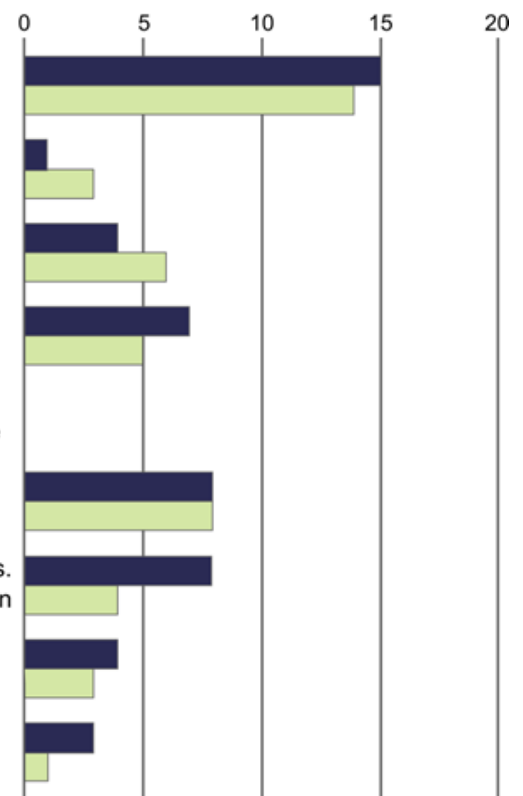

Figure 5: Students' evaluation of the exhibition project, open answers grouped thematically. N=44.

When asking the students whether they were satisfied with the exhibition as the result of the project, and what they would change next time, $72 \%$ answered that they were very satisfied or were satisfied (art course $45 \%$, chemistry course $96 \%$, cf. Figure 6). The difference between the two courses is considerable: Whereas the chemistry team was overall very satisfied with the resulting exhibition, the art team was much more self-critical, usually answering "yes, but..." and making suggestions about what should be changed next time. Similarly, the numerous answers in the category 'other answers' were suggestions of what to improve so the project would run smoother next time.

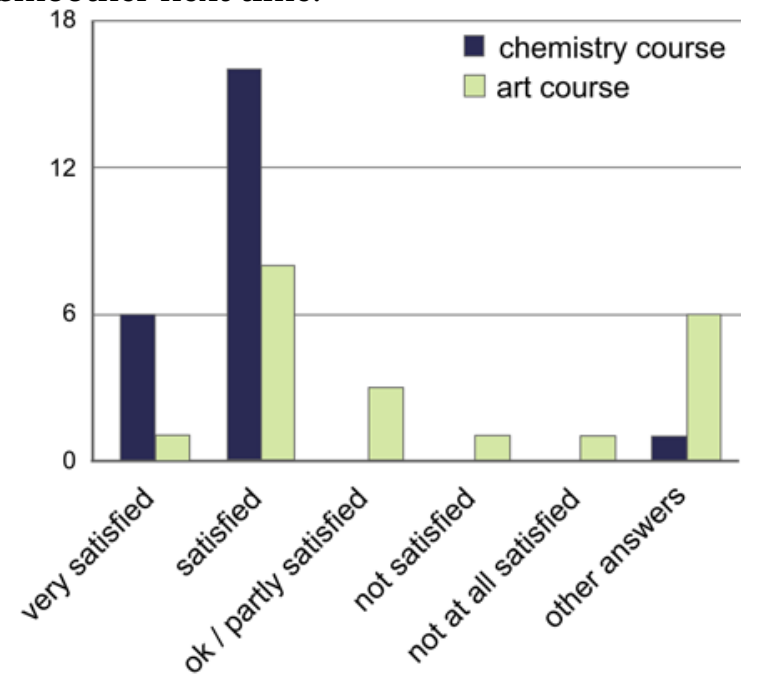

Figure 6: Students' overall attitudes towards their experience of developing an SCE. Free text item, $\mathrm{N}=43$.

In summary, the evaluation results offer interesting insights into how much time students spend on an exhibition project, how their motivation changes during the project, and what 
they like or dislike within such a project. The next step will be a closer investigation of the potential to influence learning, especially the crossover effects between students with a scientific and an art background.

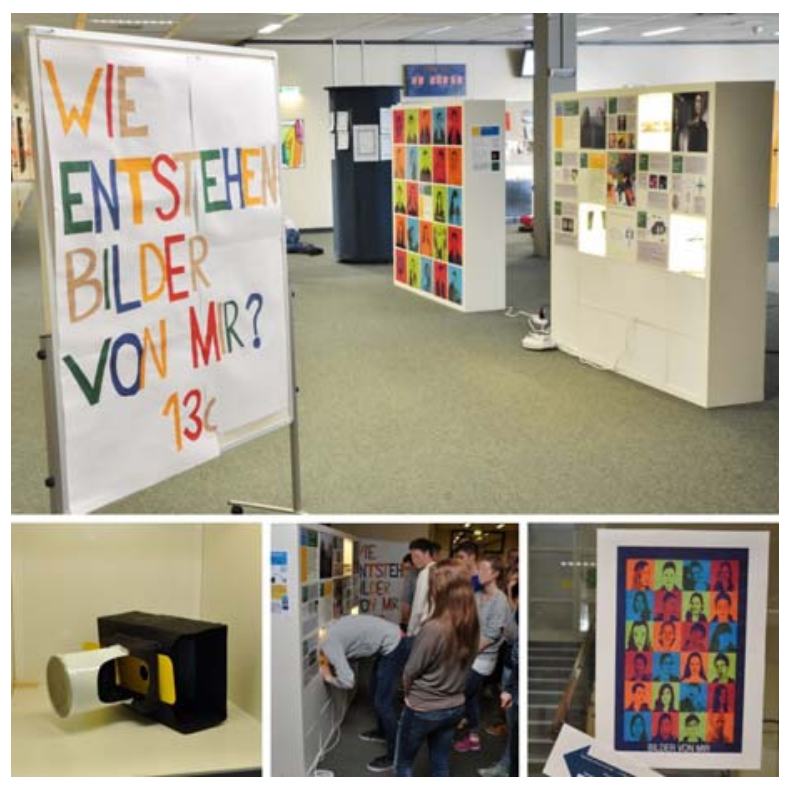

Figure 7: Impressions from a different SCE project: The exhibition 'pictures of me' was created by a $13^{\text {th }}$ grade class at the high school of Heikendorf, Schleswig-Holstein, Northern Germany. The exhibition shows different techniques of medical imaging, but also includes other photographic approaches such as thermal imaging cameras. A section on Kirlian photography and a discussion on the philosophical question of 'what is an image' completes the picture.

The feedback from the teachers who developed exhibitions with their students was predominantly positive. Although they admitted that the extra amount of time was "substantial" when doing it for the first time, they all agreed that is was feasible and would be much easier when creating the next exhibition. All of the teachers agreed that it was worth taking up the challenge of an SCE, and stated that they would do it again. The main arguments reported by the teachers for repeating an exhibition project were that "the change of perspective while focusing on the addressee increases the demand on their own performance", that "the real public exhibition increases motivation and the feeling that it was worth working for it", and, last but not least, "the dynamic that unfolds in a project like this" and "the event character (students will never forget)". Greg Kocourek, a high school teacher from Bloomington, IL puts it in a nutshell when describing his experience when developing a student exhibition: "The process of creating this unit together with my students was one of the most powerful teaching experiences I have ever had" (Weilbacher, Rojes, \& Kocourek, 2011, p.99).

\section{Conclusion}

In order to reach the goal of students becoming active members of society on both a local (i.e., expert amateur) and a global level (i.e., public engagement), and thus being able to connect to and engage in this multicultural environment, multiliteracy is a prerequisite. 
When using this extensive environment to form a personal opinion by integrating content from multiple sources, the ability to use multimodal representations in a skillful way gives students an obvious advantage.

SCEs offer a multitude of very different learning opportunities: Developing the content demands profound inquiry skills and creating a presentation with a coherent overall image requires the successful application of multimodal representations, thus training expertise in both fields. Furthermore, all of the skills identified as the '21st Century Skills' by the Partnership for 21st Century Learning (Partnership for 21st Century Learning, 2011) can be advanced in the different stages of the development of an SCE. In particular, skills highlighted as the famous '4Cs': critical thinking, communication, collaboration, and creativity, are most prominently used and trained in the development phase, but, similarly, other skills such as information literacy and media literacy could potentially also be developed. Carrying out a project with a rather complex but direct and tangible result induces quite a high level of motivation within the group of students, but also requires effective organization and project management, thereby also providing a realistic learning environment for these skills.

Although the advantages are quite obvious, the limited time available at schools is a huge barrier for the initiation and development of an SCE. Nevertheless, the projects that we completed in the last year show that SCEs are feasible - even within a tight curriculum - when attention is paid to four main issues:

- A high level of effective organization and management is required

- A clearly defined exhibition framework (like the EXPOneer system) helps to structure the content and to limit the immense scope an exhibition offers in general

- A good cooperation between all stakeholders such as teachers, classes, etc. is essential for a successful project outcome, and

- A well-defined final goal makes the work on finalizing the project easier.

The great opportunities offered by SCEs lie in their flexibility; the project can be adapted to the conditions prevailing at a school as well as to students' own experience. The proposed implementation as well as the options introduced in this article have to be seen as a collection of ideas on how to create SCEs. Further experience will be gained from the upcoming exhibitions in the IRRESISTIBLE project.

\section{Acknowledgements}

The authors would like to thank the Chemical Industry Fund (FCI) for their financial support to develop the EXPOneer system for student-curated exhibitions. Within the EU project IRRESISTIBLE (grant agreement no. 612367), student-curated exhibitions are a central part of the students' work. The project fostered many discussions on the implementation (especially with Pedro Reis), which also improved this article significantly. Without teachers such as Wilfried Wentorf, Ulrike Thoms, or Angela Empen risking the adventure of creating 
an exhibition with their students, the proof of concept wouldn't have been possible. Last but not least, we want to thank our colleagues Stefan Schwarzer and Bente Hansen for their support and fruitful discussions. 


\section{References}

Bandelli, A. (2010). Engagement tools for scientific governance. J ournal of Science Communication, (9), 1-4.

Boll, L. (2013). Entwicklung eines Fragebogens zur Untersuchung von Erwartungen und Bewertungen eines Besuchs im Schülerlabor Klick! (Master Thesis). Christian-AlbrechtsUniversität zu Kiel, Kiel.

Bybee, R. W. (2002). Learning science and the science of learning. Science Educators' Essay Collection. Arlington, VA: National Science Teachers Association.

Cazden, C., Cope, B., Fairclough, N., Gee, J ., Kalantzis, M., Kress, G., . . Nakata, N. M. (1996). A Pedagogy of Multiliteracies: Designung Social Futures. Harvard Educational Review, 66(1), 6092.

D'Acquisto, L. (2006). Learning on display: Student-created museums that build understanding. Gale virtual reference library. Alexandria, VA.: Association for Supervision and Curriculum Development.

Gamerman, E. (2014, October 23). Everybody's an Art Curator. The Wall Street J ournal. Retrieved from http:// www.wsj.com/ articles/ everybodys-an-art-curator-1414102402

Ho, C. M., Nelson, M. E., \& Müeller-Wittig, W. (2011). Design and implementation of a studentgenerated virtual museum in a language curriculum to enhance collaborative multimodal meaning-making. Computers \& Education, 57(1), 1083- 1097. doi:10.1016/j.compedu.2010.12.003

Hodge, D., Haynes, C., LePore, P., Pasquesi, K., \& Hirsh, M. (2008). From inquiry to discovery: developing the student as scholar in a networked world. Learning Through Enquiry Alliance (LTEA) Conference.

Hodson, D. (1998). Teaching and learning science: Towards a personalized approach. Buckingham, Philadelphia: Open University Press.

House of Lords - Science and Technology Committee. (2000). Science and Technology - Third Report. Retrieved from http:// www.parliament.the-stationeryoffice.co.uk/pa/ld199900/ldselect/ldsctech/38/3801.htm

J ewitt, C. (2008). Multimodality and Literacy in School Classrooms. Review of Research in Education, 32(1), 241-267. doi:10.3102/0091732X07310586

Kahn, P., \&O’Rourke, K. (2004). Guide to curriculum design: enquiry-based learning. Higher Education Academy, (30-3).

Kampschulte, L. (2014, August 29). RRI modules following the 6E-approach. [Web log post]. Retrieved from http:// www.irresistible-project.eu/index.php/ en/ blog/ 39-rri-modules-followingthe-6e-approach/

Kampschulte, L., \& Schwarzer, S. (2014). Exhibition Manual: V1. Retrieved from http:// exponeer.de/ images/ expo-mat/ EXPOneer_ExhibitionGuide.pdf

Könneker, C., \&Lugger, B. (2013). Public Science 2.0 - Back to the Future. Science (New York, N.Y.), 342(6154), 49- 50. doi:10.1126/ science.1245848

Krajcik, J., Blumenfeld, P. C., Marx, R. W., Bass, K. M., Fredricks, J ., \& Soloway, E. (1998). Inquiry in Project-Based Science Classrooms: Initial Attempts by Middle School Students. J ournal of the Learning Sciences, 7(3-4), 313- 350. doi:10.1080/ 10508406.1998.9672057

Kuhn, D., Black, J ., Keselman, A., \& Kaplan, D. (2000). The Development of Cognitive Skills To Support Inquiry Learning. Cognition and Instruction, 18(4), 495- 523. doi:10.1207/S1532690XCI1804_3

Kuznetsov, S., \& Paulos, E. (2010). Rise of the expert amateur. In E. T. Hvannberg, M. K. Lárusdóttir, A. Blandford, \&J . Gulliksen (Eds.), Proceedings of the 6th Nordic Conference on HumanComputer Interaction: Extending Boundaries (pp. 295- 304). New York, NY, USA: ACM. 
Marzano, R. J., Pickering, D., \& Pollock, J . E. (2001). Classroom instruction that works: Researchbased strategies for increasing student achievement. Alexandria, Va.: Association for Supervision and Curriculum Development.

Partnership for 21st Century Learning. (2009). P21 Framework Definitions. Retrieved from http:// www.p21.org/ storage/ documents/ P21_Framework_Definitions.pdf

Partnership for 21st Century Learning. (2011). Framework for 21st Century Learning. Retrieved from http:// www.p21.org/ storage/ documents/1._p21_framework_2-pager.pdf

Roth, W.-M., \& Lee, S. (2002). Scientific literacy as collective praxis. Public Understanding of Science, 11(1), 33- 56. doi:10.1088/ 0963-6625/ 11/ 1/ 302

Schwarzer, S., \& Parchmann, I. (2015). Erwartungen von Schülern und Wissenschaftlern an Schülerlaborbesuche. Manuscript submitted for publication, Department of Chemistry Education, IPN Kiel, Germany,

Serrell, B. (1996). Exhibit labels: An interpretive approach. Walnut Creek: Alta Mira Press.

Serrell, B. (2006). J udging exhibitions: A framework for assessing excellence. Walnut Creek, Calif.: Left Coast.

Sleeper, M., \& Sterling, D. (2004). The In-Class Science Exhibition. Science Scope, 27(6), 49- 52.

Strausbaugh, J . (2011, J uly 10). An Exhibition Whose Curator Is 17. The New York Times, pp. AR21. Retrieved from http:/ / www.nytimes.com/2011/ 07/ 10/arts/ design/ an-art-show-whose-curatoris-in-high-school.html?pagewanted=all\&_ $\mathrm{r}=0$

Swain, H. (2007). An introduction to museum archaeology. Cambridge, New York: Cambridge University Press.

Tirre, F., Kampschulte, L., \& Parchmann, I. (accepted). Ein Science Camp zu Wissenschaft und Wissenschaftskommunikation: Schüler präsentieren (ihre) Nanoforschung. ChemKon.

Weilbacher, G., Rojes, K., \& Kocourek, G. (2011). Democratic Teaching: Revisiting Type-Four Core Curriculum. Education in a Democracy: A J ournal of the NNER, 3, 85- 110. 